\title{
Health Related Quality of Life among Breast Cancer Patients: a Study from Turkey
}

\author{
Sehsuvar Gokgoz \\ Department of Surgery, Faculty of Medicine \\ Uludag University, 16059 Bursa, Turkey
}

Tel: 90-224-295-2040Ｅ-mail: sehsuvar@uludag.edu.tr

Ganime Sadikoglu

Department of Family Medicine, Faculty of Medicine

Uludag University, 16059 Bursa, Turkey

Tel: 90-224-295-4230Ｅ-mail: ganimes@uludag.edu.tr

Ela Paksoy

Department of Surgery, Faculty of Medicine

Uludag University, 16059 Bursa, Turkey

Tel: 90-224-295-2040Ｅ-mail: elapaksoy@yahoo.com

\author{
Umit Guneytepe \\ Department of Surgery, Faculty of Medicine \\ Uludag University, 16059 Bursa, Turkey
}

Tel: 90-224-295-2040Ｅ-mail: drguneytepe@yahoo.com.tr

Alis Ozcakir

Department of Family Medicine, Faculty of Medicine

Uludag University, 16059 Bursa, Turkey

Tel: 90-224-295-42-30Ｅ-mail: alis@uludag.edu.tr

\author{
Nuran Bayram \\ Department of Econometrics, Faculty of Economics and Administrative Sciences \\ Uludag University, 16059 Bursa, Turkey \\ Tel: 90-224-442-89-40Ｅ-mail: nuranb@uludag.edu.tr \\ Nazan Bilgel (Corresponding author) \\ Department of Family Medicine, Faculty of Medicine \\ Uludag University, 16059 Bursa, Turkey \\ Tel: 90-224-442-8599Ｅ-mail: nazan@uludag.edu.tr
}

Received: December 14, 2010 Accepted: January 5, 2011 doi:10.5539/gjhs.v3n2p140 


\begin{abstract}
The purpose of this study was to assess the quality of life of 123 newly diagnosed breast cancer patients who had been followed up after the initial treatment by the outpatient clinic for breast surgery of a university hospital. The Turkish version of QLQ-C30 (Quality of Life Questionnaire-Cancer 30) and QLQ-BR23 (Quality of Life Questionnaire- Breast Cancer 23) were used to measure the quality of life. The mean score for global heath status/ QOL was 64.43. Patients with localized cancer had higher scores. Those in the advanced stages of breast cancer had lower physical, social and sexual functioning than those in the early stages. Patients who were currently receiving chemotherapy had lower global health/QOL, significantly different from those receiving only hormone therapy. Breast cancer patients experience problems in multiple quality of life domains. Health professionals must recognize and take into consideration the importance of QOL, in order to improve the health of breast cancer patients.
\end{abstract}

Keywords: Breast cancer, Quality of life, QLQ-C30, QLQ-BR23, Turkey

\title{
1. Introduction
}

Worldwide, breast cancer is the most common malignancy among women, with an estimated 715,000 new cases for the year 2008 diagnosed in the more developed regions (26.5\% of the total) and 577,000 (18.8\%) in less developed countries (WHO-IARC, 2008). Breast cancer is also the most important cause of neoplastic deaths among women; the estimated number of deaths in 2002 was 410,000 worldwide (WHO-IARC, 2008). In developed countries, survival from breast cancer has slowly increased to the current rate of $85 \%$, following improvements in screening practices and treatments. On the other hand, the survival rate in developing countries remains around 50-60\% (WHO-IARC, 2008).

In Turkey, breast cancer is responsible for the largest proportion of female deaths from any form of cancer, and has accounted for approximately $16.7 \%$ of all cancer-related deaths in recent years (IARC, 2002). Furthermore, breast cancer is responsible for the largest proportion of new cancers that are reported in Turkey, making up $24.2 \%$ of female cancers (IARC, 2002). The incidence of breast cancer among women in Turkey was found to be 35.47 per 100,000 in the year 2005 (KETEM, 2005).

While early detection and treatment, along with advances in treatment are expected to result in better rates of survival, problems related to the treatment can cause negative effects on health related quality of life. Today QOL of patients is considered an important issue in the treatment of women with breast cancer (Ahn et al., 2007; Jayasekara et al., 2008; Kontodimopoulos, 2010; Montazeri, 2008; Montazeri et al., 2000; 2008; Munshi et al., 2010; Potter et al., 2009; Salonen et al., 2009)

The time of diagnosis, initial stages of the treatment course and the months following the end of the treatment are hard times for patients both physically and emotionally. During these periods poor adjustment and decreased quality of life in breast cancer patients can easily occur (Frost et al., 2000; Schnipper, 2001). Studies have shown that decreased QOL as a result of chemotherapy side effects may predict early treatment discontinuation in patients (Richardson et al., 2007). Randomized clinical trials revealed that the use of chemotherapy, especially more aggressive chemotherapy, was associated with worse QOL than was seen with hormonal interventions or less aggressive chemotherapy (Fairclough et al., 1999; Goodwin et al., 2003; Hurny et al., 1997; Levine et al., 1998). The HRQOL data are intended to help guide clinical decision-making regarding selection of the optimal treatment, to provide information about the experience of patients receiving treatment and potentially to predict prognosis (Goodwin et al., 2003). However, currently it is not clear whether health related QOL measurements influence clinical decision-making or whether the contribution of QOL measurement to clinical decision-making varies according to the stage of the disease or the type of intervention (Goodwin et al., 2003).

In Turkey health related QOL among cancer patients is a neglected subject. Compared to western literature there are few published studies which encompass health related QOL among breast cancer patients in Turkey (Akin et al., 2008; Alicikus et al., 2009; Karakoyun-Celik et al., 2010; Uzun et al., 2004). One of the previous studies (Alicikus et al., 2009) evaluated only psychosexual and body image aspects of QOL by comparing breast conserving treatment and mastectomy. Other one measured QOL and self efficacy among Turkish breast cancer patients undergoing chemotherapy (Akin et al., 2008). Another study used a different quality of life scale which was not specifically designed for breast cancer patients but for measuring quality of life in general (Uzun et al., 2004) and the last study used the same QOL instruments which we have also used in this study but they did the quality of life evaluations only in terms of depression and anxiety. Therefore it can be said that our study is the first study performed among Turkish breast cancer patients by using the QOL-BR23 instrument for the evaluation of QOL in a broader sense. There are also few studies on translation and validation of various QOL measures for Turkish cancer patients (Can \& Aydiner, 2009; Can et al., 2010; Cankurtaran et al., 2008; Bektas and Akdemir, 
2008; Guzelant et al., 2004; Hoopman et al., 2006) and all of these studies were performed in order to validate the Turkish versions of QOL-C30 and QOL-BR23 instruments.

The purpose of this study was to assess the quality of life of breast cancer patients who had been followed up after the initial treatment by the outpatient clinic for breast surgery of Uludag University hospital in Bursa Turkey.

\section{Material and methods}

\subsection{Research setting and study participants}

This study was performed at the outpatient clinic for breast surgery of Uludag University Hospital in Bursa/Turkey. The study group comprised patients who were followed up for breast cancer at this clinic. During a period of two months 179 patients attended for follow-up. All of the followed patients were informed about the purpose and anonymity of study and asked if they would like to participate to the study voluntarily. Hundred fifty eight patients wanted to participate and gave their written consent. Due to missing data, 35 participants were excluded, so the final study group consisted of 123 patients. Approval for this study was granted by the Ethics Committee of the Uludag University. The questionnaires regarding the demographic characteristics and QOL were completed by the participants. The medical history data regarding breast cancer were gathered by the authors from the medical records of the corresponding participants.

\subsection{Instruments}

The EORTC (European Organization of Research and Treatment for Cancer) QLQ-C30 version 3.0 is a 30-item core cancer specific questionnaire measuring QOL in cancer patients (Aaronson et al., 1993). This self-administered questionnaire incorporates five functional scales: Physical (PF), role (RF), cognitive (CF), emotional (EF) and social (SF), three symptom scales for fatigue, pain and nausea/vomiting, a global health QOL scale, and several single items for the perceived financial impact of disease and treatment and for the assessment of additional symptoms such as dyspnoea, appetite loss, sleep disturbance, constipation and diarrhea which are commonly reported by cancer patients. All items were scored on 4-point Likert scales ranging from 1 (not at all) to 4 (very much). As an exception, item 29 and 30 in the global health QOL subscale were scored on a modified 7 point linear analogue scale (Fayers et al., 2001). All functional scales and individual item scores were transformed to a 0-100 scale with higher values indicating a higher functioning in functional scales and an increased presence of symptoms in symptom scales. Approval was obtained from EORTC Quality of Life Group. We used the Turkish version of the questionnaire which had been validated in previous studies (Cankurtaran et al., 2008; Guzelant et al., 2004; Hoopman et al., 2006, Ozturk et al., 2009).

The EORTC QLQ-BR23 is a 23-item breast cancer-specific questionnaire about the common side effects of therapy, body image, sexuality, and outlook for the future (Jayasekara, et al., 2008; Montazeri et al., 2008). All items were scored on 4-point Likert scales ranging from 1 (not at all) to 4 (very much). The scoring approach for the QLQ-BR23 is identical in principle to that for the function and symptom scales/single items of the QLQ-C30. We used the Turkish version of the QLQ-BR23 which was obtained from the EORTC Quality of Life Group.

\subsection{Analysis}

Statistical analyses were performed using Statistical Package for Social Sciences 13.0 program for Windows (SPSS Inc, Chicago, IL). Scale internal consistency reliability was assessed via Cronbach's alpha and the 0.70 standard for group level comparisons was adopted (Nunnaly \& Bernstein, 1994). Construct validity was assessed by the interscale correlations between QLQ-C30 and QLQ-BR23, and the assumption that conceptually related scales would correlate substantially, and conversely scales with less in common would show lower correlations (Aaronson et al., 1993; Jayasekara et al., 2008). Calculation of the quality of life scores from both of the study instruments were performed according to the scoring manual developed by the EORTC study group (Fayers et al. 2001). Quality of life scores were compared with demographic and clinical parameters in order to understand the patterns. Student-t test and variance analysis (one way ANOVA and Kruskall-Wallis) were used to test the statistical significance of differences in between the groups. All results were regarded as statistically significant at $\mathrm{p}<0.05$.

\section{Results}

\subsection{Patients' demographic and clinical characteristics}

The patients' mean age was $49.37 \pm 9.55$ years (Mean \pm SD) with a range of 27-67 years. Most of the patients were married (91.1\%), primary school graduates (56.9\%) and housewives (67.5\%). The median length of time since the diagnosis of cancer was twenty four months (Mean $\pm \mathrm{SD}=43.46 \pm 42.30$ months; range $4-168$ months). Fifty five point three percent of patients had a local cancer at the time of diagnosis and $25.2 \%$ were at stage I, $35.0 \%$ at stage 
II and $23.6 \%$ at stage III whereas $1.6 \%$ and $6.5 \%$ were at stages 0 and IV respectively. According to the type of cancer, 58.5\% had invasive ductal and 3.3\% invasive lobular cancer and some 38.2\% other types. Most of the patients had undergone surgical treatment (57.7\%) followed by combined therapies (23.5\%). Other therapies were only chemotherapy (16.4\%) and only radiotherapy (2.4\%). Most of the surgically treated patients had undergone mastectomy (50.5\%) followed by breast conserving surgery (35.1\%). At the time of the study $40.6 \%$ of the patients were receiving no therapy whereas $30.1 \%$ were having hormone and $29.3 \%$ chemotherapy.

\subsection{QLQ-C30 and QLQ-BR23 scales}

Data on central tendency and reliability of QLQ-C30 and QLQ-BR23 scales are presented in Table 1. Throughout both instruments all of the scales met the 0.70 internal consistency criterion. Among the items of QLQ-C30 nausea/vomiting, dyspnoea, appetite loss, constipation, and diarrhoea had high minimum scores ( $>50 \%)$ implying a lack of these symptoms in this sample but may also be hinting about an underlying reduced discriminative ability. Among the scales/items of QLQ-BR23 the sexual functioning scale also had a high minimum score, and this may reflect the diminished sexual functioning, but may also point to an underlying discriminative ability.

\section{$<$ Table $1>$}

The QLQ-BR23 scale showed high correlations (Table 2) with QLQ-C30 scale in 78 out of 105 comparisons (74.0\%). Global health status/QOL and emotional functioning were correlated to all of the functional and symptom scales of QOL-BR-23. Whereas body image, sexual functioning, sexual enjoyment and future perspective were positively but therapy side effects, breast symptoms, arm symptoms and upset by hair loss negatively correlated. Emotional and social functioning were strongly and positively correlated to body image. Cognitive functioning was strongly and negatively correlated to therapy side effects. Physical functioning was correlated to all of the functional and symptom scales of QOL-BR23 except body image and upset by hair loss.

$<$ Table 2>

The correlations between QLQ-BR23 subscales also showed high correlations and in 19 out of 28 comparisons (67.8\%) significant correlations were observed. Future perspective was strongly and positively correlated to body image and upset by hair loss was strongly and negatively correlated to body image and future perspective.

\subsection{QOL according to some demographic characteristics}

We compared the mean scores of functional scales related to QLQ-C30 and QLQ-BR23 in patients of different age groups and educational attainment. We did not find a significant difference in terms of global health status/QOL among patients of different educational status. There was a significant difference in terms of body image among patients of different educational status and those with primary education had the highest score (77.38 \pm 22.57$)$.

We did not find a significant difference among different age groups in terms of global health/QOL status. Those who were 50 years of age and older had the highest scores in emotional $(76.69 \pm 20.34)$, social $(88.13 \pm 16.39)$ functioning and body image (78.53 \pm 20.00$)$.

\subsection{QOL according to some characteristics of breast cancer and treatment}

The mean scores for QLQ-C30 and QLQ-BR23 scales according to the localization of breast cancer at diagnosis are shown in Table 3. The global health status of patients with localised breast cancer was found to be higher than those with local and axillary located breast cancer. A similar result was obtained for cognitive functioning. Among the symptom scales of QLQ-C30 the pain score was higher among patients with local and axillary breast cancer whereas appetite loss was higher among patients with local breast cancer. According to the QLQ-BR23 scale sexual functioning was better among patients with localised breast cancer and fewer arm symptoms were observed than in patients with local and axillary located breast cancer

\section{$<$ Table 3>}

The comparison of QOL among patients in different stages of breast cancer showed significant differences in physical functioning, social functioning, sexual functioning, sexual enjoyment, pain and arm symptoms. We found no significant difference in terms of global health status/QOL among patients in different stages of breast cancer. Physical functioning among stage II patients was significantly better than those in stage III and IV (80.78 \pm 12.95 versus $69.19 \pm 19.20, \mathrm{p}=0.011)$.

Social functioning among stage II patients was significantly better than those in stage 0-1 (85.27 \pm 21.58 versus $68.69 \pm 32.74, \mathrm{p}=0.023$ ) We found no significant differences among patients in different stages in terms of symptom scales of QOL-30 except for the pain symptom which was higher among patients in stages III and IV than those in stages $0-1(32.43 \pm 23.22$ versus $18.60 \pm 17.62, \mathrm{p}=0.020)$. 
In terms of functional scales of QOL-BR23 only sexual functioning and sexual enjoyment scales were found to be significantly different among patients of different stages. Sexual functioning of patients in $0-1$ stages were significantly better than those in stages III and IV $(19.19 \pm 17.24$ versus $6.31 \pm 13.24, \mathrm{p}=0.002)$. Similar results were obtained for sexual enjoyment (37.50 \pm 11.39 versus $13.33 \pm 28.11, \mathrm{p}=0.043)$. Among symptom scales of QOL-BR23 only arm symptoms were found significantly different in patients with different stages and were higher among patients in stages III-IV than those in stages $0-1$ and II (37.84 \pm 24.77 versus $18.18 \pm 17.13$ and 24.29 $\pm 19.74, \mathrm{p}=0.001$ ).

Table 4 shows the comparison of QOL of breast cancer patients according to the current treatment. The global health status of patients who currently do not receive any treatment was found to be higher than of those receiving hormone therapy or chemotherapy. Similar results were obtained for physical, role and social functioning. Sexual functioning and sexual enjoyment were found to be lower among patients who currently receive chemotherapy and symptoms such as fatigue, nausea/vomiting, insomnia, appetite loss, systemic therapy side effects and breast symptoms were more frequently seen among patients who currently receive chemotherapy.

$<$ Table 4>

The comparison of QOL of patients according to the time passed since diagnosis is shown in Table 5. Role functioning and sexual enjoyment was found to be higher among patients who had been diagnosed with breast cancer for five years or more. Social functioning was better among those who had been diagnosed for 2-4 years. Pain, insomnia, appetite loss systemic therapy effects and breast symptoms were frequently seen among patients who had been diagnosed for one year or less. In terms of global health status we found no significant differences among the groups with different times since diagnosis.

\section{$<$ Table 5 >}

\section{Discussion}

In this study we assessed the HRQOL among a group of breast cancer patients who had been diagnosed, treated and followed up by a single clinic. The median and mean scores for global heath status/ QOL were 66.67 and 64.43 respectively. Median scores for the functional scales varied between 75.00 and 83.33 in terms of QLQ-C30 scale. When the breast cancer specific QLQ-BR23 scale was taken into account, the median scores for the functional scales were between 33.33 and 83.33 except sexual functioning. Most of the patients (56.9\%) scored 0 points in terms of sexual functioning. In western literature the prevalence of sexual dysfunction is reported to be between $40 \%$ and $100 \%$ however it is hard to define a certain rate due to ethnic and cultural differences (Ganz et al., 1998; Schover, 1991). A study among Turkish breast cancer patients showed no significant correlation between depression and QQL scores related to sexuality and this condition is contributed to by the nature of Turkish women having fewer expectations of sexual life and their timidity when answering the question in this module due to their cultural and social behaviour (Karakoyun-Celik et al., 2010). Among the symptom scale scores the highest values were for fatigue, financial difficulties, insomnia and pain whereas for the breast cancer specific symptoms these were distress about hair loss, systemic therapy side effects, arm symptoms and breast symptoms respectively. Previous studies among breast cancer patients in Turkey using different QOL instruments showed similar moderate QOL scores (Akin et al., 2008; Ogce et al., 2007; Uzun et al., 2004).

Studies have concluded that there is a negative relationship between age and physical and emotional well-being among breast cancer patients (Avis et al., 2005; Lu et al., 2007; Vacek et al., 2003). We did not find significant differences in terms of global health status/QOL among patients who were younger than 50 years and 50 years of age or older. However, emotional and social functioning and perception of body image were significantly better among patients who were 50 years of age and older. A study among Turkish breast cancer patients which used a different HRQQL measure found that the overall quality of life and its dimensions were more negatively affected in younger patients (Akin et al., 2008). The results of all these studies draw attention to young breast cancer patients who may need more physical, emotional and social support. Why younger patients were more negatively affected? This issue needs further evaluation but one explanation could be that physical appearance is more important in younger ages and women whose image has been changed because of hair loss and surgical interventions could feel themselves emotionally depressed and this feeling may hinder them to take part in social activities.

Many studies have reported that educational level has an effect on quality of life (Akin et al., 2008; Cui et al., 2004; Guner at al., 2006; Pandey et al., 2005; Spagnola et al., 2003). We found no significant relationship among women with different educational levels in terms of global health status/QOL but physical functioning and body image were found to be better among those who were primary school graduates. Why primary school graduated patients got better scores for physical functioning and body image than those with more education needs to be further 
studied. The perception of self-efficacy, the value of life and the ability of adapting simple coping mechanisms may be some of the reasons for this finding.

In general patients with advanced cancer have more difficulty in adjusting and they experienced greater distress than those with early stage disease (Akin et al., 2008; Bull et al., 1999; Cui et al., 2004; Ogce et al., 2007). Our findings indicated that patients with advanced stage breast cancer had lower physical, social and sexual functioning than those with early stage cancer and they also presented with more arm symptoms and pain. However, we did not find significant differences in terms of global health status/QOL among patients at different stages of the disease.

Some studies have shown the negative impact of chemotherapy on HRQOL of breast cancer patients (Akin et al., 2008; Lee et al., 2001). Our results were consistent with the results of previous studies and we found that patients who were currently receiving chemotherapy had lower global health/QOL, physical functioning, role functioning, social functioning and sexual functioning significantly different from those receiving only hormone therapy. Furthermore, symptoms such as fatigue, nausea/vomiting, insomnia, appetite loss, systemic therapy side affects and breast symptoms were seen more frequently among that group. Cui et al. (2004) reported that there was a relationship between the duration of breast cancer diagnosis and the general quality of life and all its dimensions. According to Kessler (2002) HRQOL is more severely affected in patients newly diagnosed with breast cancer. The results of our study showed a consistency with the results of both of these studies. However, we did not find significant differences for global health status/QOL among patients with different duration of diagnosis but the role functioning, social functioning and sexual enjoyment were better among those with longer duration whereas symptoms such as pain, appetite loss, insomnia, breast symptoms and systemic therapy effects were more common among those with shorter duration. Among the symptom scales, only the arm symptoms score was found to be higher among patients with a longer duration of breast cancer than those with shorter duration. However, another study of Turkish breast cancer patients showed that women, who had been diagnosed less than a year, had a higher overall quality of life than women for whom more than a year had passed since diagnosis (Ogce et al., 2007). Why role functioning, social functioning and sexual enjoyment were better among patients with longer duration of breast cancer is an interesting result of our study and may explained by the challenges of survivorship which are many. The searing recognition of mortality changes everything. From that moment forward all of life will be viewed through a double lens. The possibilities of both a long life and a greatly abbreviated one are appreciated. Over time this dual view may enrich their lives. They will learn to live with cancer, to go on, to take and to appreciate the dark side as well as the daylight. So they will try to do the best of their lives.

Health care professionals must recognize and take into consideration the importance of QOL, besides their treatment in order to improve the health of breast cancer patients. The results of this study would help to fill gaps in the current limited knowledge and identify areas in which patients need extra support. Since there clearly are negative effects of cancer and chemotherapy on patients' quality of life, healthcare providers need to focus on designing psychosocial interventions to improve self-care and quality of life and support the cancer patients throughout their illness and chemotherapy. This will improve cancer patients' adaptation to their disease and emotional well-being. Planned education programs addressing patients' needs, help patients by providing verbal encouragement; introducing patients to positive role models and incorporating pain management guidelines into the delivery of patient care are important interventions toward improving quality of life among breast cancer patients.

\section{Study limitations}

Despite the limitations of this study due to its small sample size and cross-sectional design, the results indicate that breast cancer patients experience problems in multiple quality of life domains and further studies are needed. Another limitation might be mixing patients with different stages and treatments. The internal consistency reliability and cross-sectional construct validity of the Turkish QLQ-C-30 and QLQ-BR-23 were satisfactorily demonstrated, but test-retest reliability and longitudinal construct validity were not addressed. Thus a longitudinal study design could be considered to overcome these limitations.

\section{Acknowledgements}

We would like to thank the EORTC for granting us permission to employ The QLQ-C30 and QLQ-BR23 scales free of charge, in this academic study. We would like to thank Mrs. C.J. Walker for editing the English language of this manuscript. This study has no conflict of interests. 


\section{References}

Aaronson, N. K., Ahmedzai, S., Bergman, B. et al. (1993). The European Organization for Research and Treatment of Cancer QLQ-C30: A quality-of-life instrument for use in international clinical trials in oncology. Journal of the National Cancer Institute, 85 (5), 365-376. http://dx.doi.org/10.1093/jnci/85.5.365

Ahn, S. H., Park, B. W., Noh, D.Y. et al. (2007). Health related quality of life in disease-free survivors of breast cancer with general population. Annals of Oncology, 18 (1), 173-182. http://dx.doi.org/10.1093/annonc/mdl333

Akin, S., Can, G., Durna, Z., Aydiner, A. (2008). The quality of life and self-efficacy of Turkish breast cancer patients undergoing chemotherapy. European Journal of Cancer Nursing, 12 (5), 449-456. http://dx.doi.org/10.1016/j.ejon.2008.07.006

Alicikus, Z. A., Gorken, I. B., Sen, R. C. et al. (2009). Psychosexual and body image aspects of quality of life in Turkish breast cancer patients: a comparison of breast conserving treatment and mastectomy. Tumori, 95 (2), 212-218. http://dx.doi.org/10.1700/422.5011

Avis, N. E., Crawford, S., \& Manuel, J. (2005). Quality of life among younger women with breast cancer. Journal of Clinical Oncology, 23 (15), 3322-3330. http://dx.doi.org/10.1200/JCO.2005.05.130

Bektas, H. A. \& Akdemir, N. (2008). Reliability and validity of the functional living index-cancer in Turkish cancer patients. Cancer Nursing, 31 (1). E1-E7. http://dx.doi.org/10.1097/01.NCC.0000305684.51884.1f

Bull, A. A., Meyerowitz, B. E., Hart. S., Apolone, G., \& Liberati, A. (1999). Quality of life in women with recurrent breast cancer. Breast Cancer Research and Treatment, 54 (1), 47-57. [Online] Available: http://www.springerlink.com/content/r410637602018311/fulltext.pdf.

Can, G. \& Aydiner, A. (2011). Development and validation of the Nightingale Symptom Assessment Scale (N-SAS) and predictors of the quality of life of the cancer patients in Turkey. European Journal of Oncology Nursing, 15 (1), 3-11. http://dx.doi.org/10.1016/j.ejon.2009.10.010

Can, G., Durna, Z., Aydiner, A. (2010). The validity and reliability of the Turkish version of the Quality of Life Index (QLI) cancer version. European Journal of Oncology Nursing, 14 (4), $316-321$. http://dx.doi.org/10.1016/j.ejon.2010.03.007

Cankurtaran, E. S., Ozalp, E., Soygur, H., Ozer, S., Akbiyik, D. I., \& Bottomley, A. (2008). Understanding the reliability and validity of the EORTC QLQ-C30 in Turkish cancer patients. European Journal of Cancer Care, 17 (1), 98-104. http://dx.doi.org/10.1111/j.1365-2354.2007.00827.x

Cui, Y., Shu, X. O., Gao, Y. et al. (2004). The long-term impact of medical and socio-demographic factors on the quality of life of breast cancer among Chinese women. Breast Cancer Research and Treatment, 87 (2), $135-147$. [Online] Available: http://www.springerlink.com/content/n02k017g571u652r/fulltext.pdf

Fairclough, D. L., Fetting, J. H., Cella, D., Wonson, W., Moinpour, C. M. (1999). Quality of life and quality adjusted survival for breast cancer patients receiving adjuvant therapy. Eastern Cooperative Oncology Group (ECOG). Quality of Life Research, 8 (8), 723-731. [Online] Available: http://www.springerlink.com/content/u38762201k280g21/fulltext.pdf

Fayers, P. M., Aaronson, N. K., Bjordal, K., Groenvold, M., Curan, D., \& Bottomley, A. (2001). On behalf of the EORTC Quality of Life Group. The EORTC QLQ-C30 Scoring Manual (3rd Edition). Published by: European Organisation for Research and Treatment of Cancer, Brussels.

Frost, M. H., Suman, V. J., \& Rummans, T. A. (2000). Physical, psychological and social well-being of women with breast cancer: the influence of disease phase. Psychooncology, 9 (3), 221-231. http://dx.doi.org/10.1002/1099-1611

Ganz, P. A., Rowland, J. H., Desmond, K., Meyerowitz, B. E., \& Wyatt, G. E. (1998). Life after breast cancer: understanding women's health-related quality of life and sexual functioning. Journal of Clinical Oncology, 16 (2), 501-514.

Goodwin, P., Black, J. T., Bordeleau, L. J., \& Ganz, P. (2003). Health related quality of life measurement in randomized clinical trials in breast cancer. Journal of the National Cancer Institute, 95 (4), $263-281$. http://dx.doi.org/10.1093/jnci/95.4.263

Guner, P., Isikhan, V., Komurcu, S., Ozturk, B., Arpaci, F., \& Ozet, A. (2006). Quality of life and Sociodemographic Characteristics of Patients with Cancer in Turkey. Oncology Nursing Forum, 33 (6), 1171-1176. http://dx.doi.org/10.1188/06.ONF.1171-1176 
Guzelant, A., Goksel, T., Ozkok, S., Tabakan, S., Aysan, T., \& Bottomley, A. (2004). The European Organization for Research and Treatment of Cancer QLQ-C30: an examination into the cultural validity and reliability of the Turkish version of the EORTC QLQ-C30. European Journal of Cancer Care, 13 (2), 135-144. http://dx.doi.org/10.1111/j.1365-2354.2003.00435.x

Hoopman, R., Muller, M. J., Terwee, C. B., \& Aaronson, N. K. (2006). Translation and validation of the QLQ-C30 for use among Turkish and Morrocan ethnic minority cancer patients in the Netherlands. European Journal of Cancer, 42 (12), 1839-1847. http://dx.doi.org/10.1016/j.ejca.2005.08.047

Hurny, C., Bernhard, J., Coates, A. S., Castiglione-Gertsch, M., Peterson, H. F., Gelber, R. (1996). Impact of adjuvant therapy on quality of life in women with node-positive operable breast cancer. International Breast Cancer Study Group. The Lancet, 347 (9011), 1279-1284. http://dx.doi.org/10.1016/S0140-6736(96)90936-8

IARC-International Agency for Research on Cancer (2002). Cancer incidence in five Continents. [Online] Available: http://www-dep.iarc.fr/ (March 25, 2007).

Jayasekara, H., Rajapaksa, L.C., \& Brandberg, Y. (2008). Measuring breast cancer specific health related quality of life in South Asia: psychometric properties of the Sinhala version of the EORTC QLQ-BR23. Quality of Life Research, 17 (6), 927-932. http://dx.doi.org/10.1007/s11136-008-9359-9

Karakoyun-Celik, O., Gorken, I., Sahin S., Orcin, E., Alanyali, H., \& Kinay, M. (2010). Depression and anxiety levels in woman under follow-up for breast cancer: relationship to coping with cancer and quality of life. Medical Oncology, 27 (1), 108-113. http://dx.doi.org/10.1007/s12032-009-9181-4

Kessler, T. A. (2002). Contextual variables, emotional state, and current and expected quality of life in breast cancer survivors. Oncology Nursing Forum, 29 (7), 1109-1116. http://dx.doi.org/10.1188/02.ONF.1109-1116

KETEM-Ministry of Health of Turkey, Cancer Early Diagnosis, Screening and Education Center, 2005. Cancer Statistics. [Online] Available: http://www.ketem.org/istatistik.php (August 10, 2010).

Kontodimopoulos, N. (2011). Validity of the Greek EORTC QLQ-C30 and QLQ-BR23 for measuring health related quality of life in breast cancer patients. European Journal of Cancer Care, 20 (3), 354-361. http://dx.doi.org/10.1111/j.1365-2354.2009.01170.x

Lee, H. L., Ku, N. P., Dow, W. J., \& Pai, I. (2001). Factors related to quality of life in breast cancer patients receiving chemotherapy. Journal of Nursing Research, 9 (3), 57-68. http://dx.doi.org/10.1097/01.JNR.0000347563.99811.ed

Levine, M. N., Bramwell, V. H., Pritchard, K. I., Norris,B.D., Shepherd, L. E., \& Abuzahra, H. (1998). Randomized trial of intensive Cyclophosphamide, epirubicin and fluorouracil chemotherapy compared with cyclophosphamide, methotrexate and fluorouracil in premenopausal women with node positive breast cancer. National Cancer Institute of Clinical Trials Group. Journal of Clinical Oncology, 16 (8), 2651-2658.

Lu, W., Cui, Y., Zheng, Y., et al. (2007). The impact of newly diagnosed breast cancer on quality of life among Chinese women. Breast Cancer Research and Treatment, 102 (2), 201-210. http://dx.doi.org/10.1007/s10549-006-9318-5

Montazeri, A. (2008). Health related quality of life in breast cancer patients: A bibliographic review of the literature from 1974 to 2007. Journal of Experimental \& Clinical Cancer Research, 27, 32. http://dx.doi.org/10.1186/1756-9966-27-32

Montazeri, A., Harirchi, I., Vahdani, M., Khaleghi, F., Jarvandi, S., \& Ebrahimi, M. (2000). The EORTC breast cancer specific quality of life questionnaire (EORTC QLQ-23): Translation and validation study of the Iranian version. Quality of Life Research, 9 (2), 177-184. [Online] Available: http://www.springerlink.com/content/m5u785668m48xj31/fulltext.pdf (August 10, 2010).

Montazeri, A., Vahdaninia, M., Harirchi, I., Ebrahimi, M., Khaleghi, F., \& Jarvandi, S. (2008). Quality of life in patients with breast cancer before and after diagnosis: an eighteen months follow-up study. BMC Cancer, 8, 330 . http://dx.doi.org/10.1186/1471-2407-8-330

Munshi, A., Dutta, D., Kakkar, S., Budrukkar, A., Jalali, R., Sarin, R. et al. (2010). Comparison of early quality of life in patients treated with radiotherapy following mastectomy or breast conservation therapy: A prospective study. Radiotherapy and Oncology, 97 (2), 288-293. http://dx.doi.org/101016/j.radonc.2010.04.008

Nunnaly, J. C. \& Bernstein, I. R. (1994). Psychometric Theory (3rd. Ed.). McGraw -Hill, New York.

Ogce, F., Ozkan, S., \& Baltalarli, B. (2007). Psychosocial stressors, social support and socio-demographic variables as determinants of quality of life of Turkish breast cancer patients. Asian Pacific Journal of Cancer 
Prevention, $\quad 8 \quad$ (1), $\quad$ 77-82. $\quad$ Available: http://www.apocp.org/cancer_download/Volume8_No1/Filiz_Ogce77-82.pdf (August 8, 2010).

Ozturk, A. Sarihan, S., Ercan, I., \& Karadag, M. (2009). Evaluating quality of life and pulmonary function of long-term survivors of non-small cell lung cancer treated with radical or postoperative radiotherapy. American Journal of Clinical Oncology, 32 (1), 65-72. http://dx.doi.org/10.1097/COC.0b013e31817e6ec2

Pandey, M., Thomas, B. C., SreeRekha, P., Ramdas, K., Ratheesan, K., Parameswaran, S., et al. (2005). Quality of life determinants in women with breast cancer undergoing treatment with curative intent. World Journal of Surgical Oncology, 3: 63. http://dx.doi.org/10.1186/1477-7819-3-63

Potter, S., Thomson, H. J., Greenwood, R. J., Hopwood, P., \& Winters, Z. E. (2009). Health related quality of life assessment after breast construction. British Journal of Surgery, 96 (6), 613-620. http://dx.doi.org/10.1002/bjs.6605

Richardson, L., Wang, W., Hartzema-Pharm, A. G., \& Wagner, S. (2007). The role of health related quality of life in early discontinuation of chemotherapy for breast cancer. The Breast Journal, 13 (6), 581-587. http://dx.doi.org/10.1111/j.1524-4741.2007.00512.x

Salonen, P., Tarkka, M. T., Kellokumpu-Lehtinen, P. L., Astedt-Kurki, P., Luukkaala, T., Kaunonen, M. (2009). Telephone intervention and quality of life in patients with breast cancer. Cancer Nursing, 32 (3), 177-189. http://dx.doi.org/10.1097/NCC.0b013e31819b5b65

Schnipper, H. H. (2001). Life after breast cancer. Journal of Clinical Oncology, 19, 3581-3584.

Schover, L.R. (1991). The impact of breast cancer on sexuality, body image, and intimate relationships. CA: A Cancer Journal for Clinicians, 41 (2), 112-120. http://dx.doi.org/10.3322/canjclin.41.2.112

Spagnola, S., Zabora, J., Brintzenhofeszoc, K., Hooker, C., Cohen, G., Baker, F. (2003). The satisfaction with life domains scale for breast cancer (SLDS-BC). The Breast Journal, 9 (6), 463-471. http://dx.doi.org/10.1046/j.1524-4741.2003.09603.x

Uzun, O., Aslan F. E., Selimen, D., \& Koc, M. (2004). Quality of life in women with breast cancer in Turkey. Journal of Nursing Scholarship, 36 (3), 207-213. http://dx.doi.org/10.1111/j.1547-5069.2004.04039.x

Vacek, P. M., Winstead-Fry, P., Secker-Walker, R. H., Hooper, G. J., \& Plante, D. A. (2003). Factors influencing quality of life in breast cancer survivors. Quality of Life Research, 12 (5), 527-537. [Online] Available: http://www.springerlink.com/content/q351p74w05925782/fulltext.pdf (August 10, 2010).

WHO-IARC-World Health Organization International Agency for Research on Cancer (2008). Breast Cancer. In: World Cancer Report 2008. (Eds.) Peter Boyle \& Bernard Levin, pp. 412-417. IARC Publications, Lyon. 
Table 1. Means, standard deviations (SD) and Cronbach Alpha values of the QLQ-C30 and QLQ-BR23 Scales

\begin{tabular}{|c|c|c|c|}
\hline & Variables & Mean \pm SD & C.Alpha \\
\hline \multirow{17}{*}{ 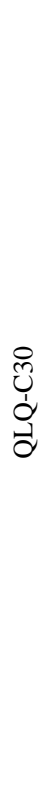 } & Global health status /QOL & $64.43 \pm 25.70$ & 0.95 \\
\hline & Functional scales & & \\
\hline & Physical functioning & $75.23 \pm 17.83$ & 0.73 \\
\hline & Role functioning & $79.40 \pm 25.26$ & 0.81 \\
\hline & Emotional functioning & $71.75 \pm 24.88$ & 0.87 \\
\hline & Cognitive functioning & $79.54 \pm 21.85$ & 0.70 \\
\hline & Social functioning & $78.32 \pm 26.30$ & 0.79 \\
\hline & Symptom scales / items & & \\
\hline & Fatigue & $39.48 \pm 25.26$ & 0.83 \\
\hline & Nausea and vomiting & $16.80 \pm 27.12$ & 0.79 \\
\hline & Pain & $24.39 \pm 22.71$ & 0.72 \\
\hline & Dyspnoea & $12.74 \pm 21.13$ & N/A \\
\hline & Insomnia & $25.20 \pm 28.10$ & N/A \\
\hline & Appetite loss & $16.80 \pm 27.45$ & N/A \\
\hline & Constipation & $16.80 \pm 23.13$ & N/A \\
\hline & Diarrhoea & $9.21 \pm 20.15$ & N/A \\
\hline & Financial difficulties & $34.42 \pm 35.18$ & N/A \\
\hline \multirow{10}{*}{ 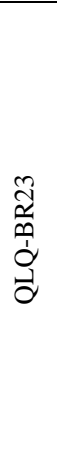 } & Functional scales & & \\
\hline & Body image & $71.61 \pm 28.25$ & 0.90 \\
\hline & Sexual functioning & $14.36 \pm 18.40$ & 0.92 \\
\hline & Sexual enjoyment & $26.78 \pm 24.96$ & N/A \\
\hline & Future perspective & $55.83 \pm 34.80$ & N/A \\
\hline & Symptom scales / items & & \\
\hline & Systemic therapy side effects & $29.15 \pm 19.67$ & 0.75 \\
\hline & Breast Symptoms & $23.44 \pm 21.22$ & 0.78 \\
\hline & Arm Symptoms & $26.38 \pm 21.78$ & 0.71 \\
\hline & Upset by Hair Loss & $38.71 \pm 38.27$ & N/A \\
\hline
\end{tabular}

Table 2. Correlations between QLQ-C30 and QLQ-BR23 scales

\begin{tabular}{|l|c|c|c|c|c|c|c|c|}
\hline & $\begin{array}{c}\text { Body } \\
\text { Image }\end{array}$ & $\begin{array}{c}\text { Sexual } \\
\text { Functioning }\end{array}$ & $\begin{array}{c}\text { Sexual } \\
\text { Enjoyment }\end{array}$ & $\begin{array}{l}\text { Future } \\
\text { perspective }\end{array}$ & $\begin{array}{l}\text { Therapy } \\
\text { side effects }\end{array}$ & $\begin{array}{c}\text { Breast } \\
\text { Symptoms }\end{array}$ & $\begin{array}{c}\text { Arm } \\
\text { Symptoms }\end{array}$ & $\begin{array}{c}\text { Upset by } \\
\text { Hair Loss }\end{array}$ \\
\hline $\begin{array}{l}\text { Global health status / } \\
\text { QOL }\end{array}$ & $.360^{* *}$ & $.268^{* *}$ & $.412^{* *}$ & $.416^{* *}$ & $-.420^{* *}$ & $-.482^{* *}$ & $-.367^{* *}$ & $-.366^{* *}$ \\
\hline Physical functioning & .125 & $.405^{* *}$ & $.381^{* *}$ & $.309^{* *}$ & $-.413^{* *}$ & $-.477^{* *}$ & $-.414^{* *}$ & -.013 \\
\hline Role functioning & $.289^{* *}$ & $.358^{* *}$ & $.357^{* *}$ & $.283^{* *}$ & $-.342^{* *}$ & $-.494^{* *}$ & $-.274^{* *}$ & -.023 \\
\hline Emotional functioning & $.621^{* *}$ & $.232^{* *}$ & $.271^{*}$ & $.637^{* *}$ & $-.644^{* *}$ & $-.303^{* *}$ & $-.269^{* *}$ & $-.490^{* *}$ \\
\hline Cognitive functioning & $.204^{*}$ & $.261^{* *}$ & $.350^{* *}$ & $.377^{* *}$ & $-.620^{* *}$ & -.160 & $-.375^{* *}$ & -.130 \\
\hline Social functioning & $.643^{* *}$ & .141 & .091 & $.577^{* *}$ & $-.485^{* *}$ & $-.371^{* *}$ & $-.297^{* *}$ & $-.289^{*}$ \\
\hline Fatigue & $-.359^{* *}$ & $-.191^{*}$ & -.094 & $-.421^{* *}$ & $.580^{* *}$ & $.375^{* *}$ & $.431^{* *}$ & .224 \\
\hline Nausea and vomiting & -.130 & -.132 & -.198 & $-.298^{* *}$ & $.526^{* *}$ & .097 & .040 & $.363^{* *}$ \\
\hline Pain & $-.222^{*}$ & $-.300^{* *}$ & -.237 & $-.400^{* *}$ & $.530^{* *}$ & $.519^{* *}$ & $.481^{* *}$ & $.315^{*}$ \\
\hline Dyspnoea & $-.190^{*}$ & -.170 & -.022 & $-.182^{*}$ & $.295^{* *}$ & $.415^{* *}$ & $.319^{* *}$ & .082 \\
\hline Insomnia & $-.411^{* *}$ & $-.248^{* *}$ & $-.297^{*}$ & $-.389^{* *}$ & $.487^{* *}$ & $.437^{* *}$ & $.214^{*}$ & .190 \\
\hline Appetite loss & $-.184^{*}$ & -.139 & -.078 & $-.303^{* *}$ & $.454^{* *}$ & .069 & -.108 & .175 \\
\hline Constipation & .056 & .006 & -.202 & -.111 & $.293^{* *}$ & .082 & .053 & .149 \\
\hline Diarrhoea & .055 & -.065 & .169 & -.142 & $.269^{* *}$ & $.204^{*}$ & .120 & .090 \\
\hline Financial difficulties & -.093 & -.066 & -.076 & -.020 & $.345^{* *}$ & $.198^{*}$ & $.264^{* *}$ & -.190 \\
\hline
\end{tabular}

Correlation is significant at the 0.01 level (2-tailed). $*$ Correlation is significant at the 0.05 level (2-tailed) 
Table 3. QOL and localization of breast cancer

\begin{tabular}{|c|c|c|c|c|}
\hline & & \multicolumn{2}{|c|}{ Localization at diagnosis } & \multirow[b]{2}{*}{$\mathrm{p}$} \\
\hline & Variables & $\begin{array}{l}\text { Local } \\
(\mathrm{N}=68)\end{array}$ & $\begin{array}{l}\text { Local \& axillary } \\
\qquad(\mathrm{N}=55)\end{array}$ & \\
\hline \multirow{17}{*}{  } & Global health status /QOL & $68.87 \pm 23.69$ & $58.94 \pm 27.21$ & .032 \\
\hline & Functional scales & & & \\
\hline & Physical functioning & $76.27 \pm 17.71$ & $73.94 \pm 18.07$ & .473 \\
\hline & Role functioning & $81.86 \pm 25.87$ & $76.36 \pm 24.36$ & .231 \\
\hline & Emotional functioning & $72.55 \pm 22.81$ & $70.76 \pm 27.40$ & .693 \\
\hline & Cognitive functioning & $83.33 \pm 17.75$ & $74.85 \pm 25.43$ & .039 \\
\hline & Social functioning & $80.88 \pm 28.54$ & $75.15 \pm 23.10$ & .221 \\
\hline & Symptom scales / items & & & \\
\hline & Fatigue & $38.73 \pm 25.72$ & $40.40 \pm 24.88$ & .716 \\
\hline & Nausea and vomiting & $17.65 \pm 26.99$ & $15.76 \pm 27.48$ & .702 \\
\hline & Pain & $20.59 \pm 21.57$ & $29.09 \pm 23.40$ & .038 \\
\hline & Dyspnoea & $12.75 \pm 23.06$ & $12.73 \pm 18.69$ & .996 \\
\hline & Insomnia & $23.53 \pm 32.10$ & $27.27 \pm 22.31$ & .448 \\
\hline & Appetite loss & $22.55 \pm 32.29$ & $9.70 \pm 17.77$ & .006 \\
\hline & Constipation & $14.71 \pm 21.84$ & $19.39 \pm 24.59$ & .265 \\
\hline & Diarrhoea & $9.80 \pm 20.81$ & $8.48 \pm 19.48$ & .720 \\
\hline & Financial difficulties & $30.39 \pm 35.84$ & $39.39 \pm 34.00$ & .159 \\
\hline \multirow{10}{*}{$\begin{array}{l}\stackrel{m}{2} \\
\frac{\alpha}{m} \\
\dot{\alpha} \\
\stackrel{\sigma}{\sigma}\end{array}$} & Functional scales & & & \\
\hline & Body image & $72.06 \pm 29.99$ & $71.06 \pm 26.20$ & .846 \\
\hline & Sexual functioning & $18.14 \pm 19.69$ & $9.70 \pm 15.61$ & .009 \\
\hline & Sexual enjoyment & $30.08 \pm 25.61$ & $20.00 \pm 22.69$ & .140 \\
\hline & Future perspective & $56.86 \pm 35.06$ & $54.55 \pm 34.76$ & .715 \\
\hline & Symptom scales / items & & & \\
\hline & Side effects & $30.81 \pm 18.98$ & $27.10 \pm 20.47$ & .300 \\
\hline & Breast Symptoms & $24.75 \pm 22.81$ & $21.82 \pm 19.14$ & .448 \\
\hline & Arm Symptoms & $20.92 \pm 19.15$ & $33.13 \pm 23.08$ & .002 \\
\hline & Upset by Hair Loss & $39.13 \pm 39.32$ & $37.50 \pm 36.26$ & .885 \\
\hline
\end{tabular}


Table 4. QOL of patients according to their current treatment

\begin{tabular}{|c|c|c|c|c|c|c|}
\hline & & \multicolumn{3}{|c|}{ Current treatment } & \multirow[b]{2}{*}{$\mathrm{p}$} & \multirow[b]{2}{*}{ Post Hoc* } \\
\hline & & $\begin{array}{l}\text { Hormone } \\
(\mathrm{N}=37)\end{array}$ & $\begin{array}{l}\text { Chemotherapy } \\
\qquad(\mathrm{N}=36)\end{array}$ & $\begin{array}{l}\text { None } \\
(\mathrm{N}=50)\end{array}$ & & \\
\hline \multirow{17}{*}{$\begin{array}{l}\stackrel{0}{0} \\
\dot{U} \\
\dot{\sigma} \\
\ddot{\sigma}\end{array}$} & GHS /QOL & $65.09 \pm 24.75$ & $50.00 \pm 25.51$ & $74.33 \pm 21.81$ & .000 & I $>$ II; III $>$ II \\
\hline & Functional scales & & & & & \\
\hline & Physical functioning & $79.28 \pm 14.55$ & $66.67 \pm 19.26$ & $78.40 \pm 17.17$ & .002 & I $>$ II; III $>$ II \\
\hline & Role functioning & $86.49 \pm 17.05$ & $56.48 \pm 30.41$ & $90.67 \pm 12.67$ & .000 & I $>$ II; III $>$ II \\
\hline & $\begin{array}{l}\text { Emotional } \\
\text { functioning }\end{array}$ & $72.30 \pm 23.82$ & $63.89 \pm 29.95$ & $77.00 \pm 20.24$ & .053 & NS \\
\hline & Cognitive functioning & $86.04 \pm 18.64$ & $75.93 \pm 23.38$ & $77.33 \pm 22.27$ & .092 & NS \\
\hline & Social functioning & $72.07 \pm 30.19$ & $69.44 \pm 29.41$ & $89.33 \pm 14.97$ & .000 & $\mathrm{I}<\mathrm{III}$; II $<$ III \\
\hline & $\begin{array}{l}\text { Symptom scales / } \\
\text { items }\end{array}$ & & & & & \\
\hline & Fatigue & $37.24 \pm 25.01$ & $49.38 \pm 24.41$ & $34.00 \pm 24.43$ & .016 & $\mathrm{II}>\mathrm{III}$ \\
\hline & Nausea and vomiting & $13.51 \pm 20.35$ & $27.78 \pm 37.37$ & $11.33 \pm 20.05$ & .013 & $\mathrm{II}>\mathrm{III}$ \\
\hline & Pain & $18.92 \pm 17.64$ & $31.48 \pm 25.75$ & $23.33 \pm 22.84$ & .055 & NS \\
\hline & Dyspnoea & $9.91 \pm 15.45$ & $14.81 \pm 25.75$ & $13.33 \pm 21.30$ & .595 & NS \\
\hline & Insomnia & $18.92 \pm 22.96$ & $37.04 \pm 31.65$ & $21.3 \pm 326.73$ & .009 & II $>$ I; II $>$ III \\
\hline & Appetite loss & $12.61 \pm 19.80$ & 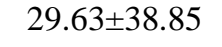 & $10.67 \pm 18.37$ & .003 & II $>$ I; II $>$ III \\
\hline & Constipation & $21.62 \pm 27.46$ & $18.52 \pm 25.75$ & $12.00 \pm 16.16$ & .138 & NS \\
\hline & Diarrhoea & $5.41 \pm 16.69$ & $9.26 \pm 18.87$ & $12.00 \pm 3.092$ & .323 & NS \\
\hline & Financial difficulties & $29.73 \pm 36.67$ & $35.19 \pm 34.68$ & $37.33 \pm 34.76$ & .605 & NS \\
\hline \multirow{10}{*}{$\begin{array}{l}\stackrel{2}{2} \\
\frac{\pi}{\infty} \\
\dot{\sigma} \\
\ddot{\sigma}\end{array}$} & Functional scales & & & & & \\
\hline & Body image & $65.77 \pm 33.55$ & $68.98 \pm 23.96$ & $77.83 \pm 26.06$ & .115 & NS \\
\hline & Sexual functioning & $17.12 \pm 15.95$ & $5.56 \pm 12.60$ & $18.67 \pm 21.47$ & .002 & I $>$ II; III $>$ II \\
\hline & Sexual enjoyment & $33.33 \pm 16.17$ & $12.50 \pm 23.96$ & $30.86 \pm 27.62$ & .025 & I $>$ II; III $>$ II \\
\hline & Future perspective & $48.65 \pm 39.75$ & $51.85 \pm 34.22$ & $64.00 \pm 30.00$ & .090 & NS \\
\hline & $\begin{array}{l}\text { Symptom scales / } \\
\text { items }\end{array}$ & & & & & \\
\hline & Side effects & $27.03 \pm 18.44$ & $39.02 \pm 22.96$ & $23.62 \pm 15.18$ & .001 & II $>$ I; II $>$ III \\
\hline & Breast Symptoms & $20.72 \pm 21.57$ &  & $18.33 \pm 20.34$ & .003 & II $>$ I; II $>$ III \\
\hline & Arm Symptoms & $30.63 \pm 21.50$ & $22.22 \pm 18.78$ & $26.22 \pm 23.73$ & .258 & NS \\
\hline & Upset by Hair Loss & $48.48 \pm 44.52$ & $40.74 \pm 42.09$ & $27.27 \pm 24.42$ & .179 & NS \\
\hline
\end{tabular}

* Tukey HSD ; NS: not significant; GHS/QOL= Global health status/ quality of life 
Table 5. QOL of patients according to the time of diagnosis

\begin{tabular}{|c|c|c|c|c|c|c|}
\hline & & \multicolumn{3}{|c|}{ Time of diagnosis } & \multirow[b]{2}{*}{$\mathrm{p}$} & \multirow[b]{2}{*}{$\begin{array}{l}\text { Post } \\
\text { Hoc* }\end{array}$} \\
\hline & Variables & $\begin{array}{c}1 \text { year or less } \\
(\mathrm{N}=42)\end{array}$ & $\begin{array}{c}2-4 \text { years } \\
(\mathrm{N}=47)\end{array}$ & $\begin{array}{c}5 \text { years or } \\
\text { more }(\mathrm{N}=34)\end{array}$ & & \\
\hline \multirow{17}{*}{ 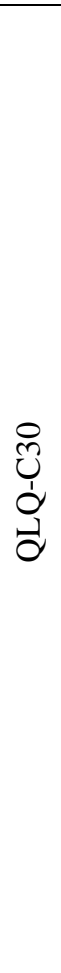 } & GHS /QOL & $63.10 \pm 24.22$ & $66.31 \pm 26.75$ & $63.48 \pm 26.59$ & .816 & NS \\
\hline & Functional scales & & & & & \\
\hline & Physical functioning & $72.38 \pm 17.08$ & $78.01 \pm 18.70$ & $74.90 \pm 17.45$ & .331 & NS \\
\hline & Role functioning & $71.43 \pm 25.58$ & $80.14 \pm 28.79$ & $88.24 \pm 15.09$ & .014 & III $>$ I \\
\hline & Emotional functioning & $68.65 \pm 27.04$ & $73.23 \pm 27.53$ & $73.53 \pm 17.46$ & .613 & NS \\
\hline & Cognitive functioning & $78.57 \pm 20.92$ & $84.04 \pm 22.24$ & $74.51 \pm 21.80$ & .144 & NS \\
\hline & Social functioning & $72.22 \pm 29.14$ & $87.23 \pm 21.48$ & $73.53 \pm 25.99$ & .011 & $\mathrm{II}>\mathrm{I}=\mathrm{III}$ \\
\hline & Symptom scales / items & & & & & \\
\hline & Fatigue & $41.27 \pm 21.15$ & $34.28 \pm 25.99$ & $44.44 \pm 28.16$ & .173 & NS \\
\hline & Nausea and vomiting & $19.05 \pm 29.58$ & $14.18 \pm 25.77$ & $17.65 \pm 26.25$ & .688 & NS \\
\hline & Pain & $29.37 \pm 23.80$ & $17.73 \pm 20.68$ & $27.45 \pm 22.43$ & .034 & $\mathrm{I}>\mathrm{II}$ \\
\hline & Dyspnoea & $14.29 \pm 19.68$ & $9.22 \pm 22.74$ & $15.69 \pm 20.49$ & .337 & NS \\
\hline & Insomnia & $34.92 \pm 32.05$ & $17.73 \pm 21.82$ & $23.53 \pm 27.86$ & .013 & $\mathrm{I}>\mathrm{II}$ \\
\hline & Appetite loss & $23.81 \pm 34.75$ & $17.02 \pm 25.89$ & $7.84 \pm 14.35$ & .040 & $\mathrm{I}>\mathrm{III}$ \\
\hline & Constipation & $17.46 \pm 24.68$ & $15.60 \pm 19.48$ & $17.65 \pm 26.25$ & .904 & NS \\
\hline & Diarrhoea & $9.52 \pm 21.19$ & $7.09 \pm 16.93$ & $11.76 \pm 23.04$ & .588 & NS \\
\hline & Financial difficulties & $36.51 \pm 34.38$ & $26.24 \pm 34.00$ & $43.14 \pm 36.26$ & .091 & NS \\
\hline \multirow{10}{*}{ 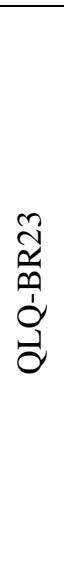 } & Functional scales & & & & & \\
\hline & Body image & $73.02 \pm 29.95$ & $76.42 \pm 23.20$ & $63.24 \pm 31.26$ & .107 & NS \\
\hline & Sexual functioning & $11.11 \pm 15.47$ & $14.18 \pm 21.97$ & $18.63 \pm 15.77$ & .209 & NS \\
\hline & Sexual enjoyment & $29.82 \pm 24.58$ & $17.95 \pm 25.35$ & $37.50 \pm 20.64$ & .036 & $\mathrm{III}>\mathrm{II}$ \\
\hline & Future perspective & $60.32 \pm 33.93$ & $59.57 \pm 31.80$ & $45.10 \pm 38.39$ & .106 & NS \\
\hline & Symptom scales / items & & & & & \\
\hline & Side effects & $36.39 \pm 20.82$ & $22.49 \pm 19.35$ & $29.41 \pm 15.48$ & .003 & $\mathrm{I}>\mathrm{II}$ \\
\hline & Breast Symptoms & $32.54 \pm 23.12$ & $16.67 \pm 16.48$ & $21.57 \pm 21.13$ & .001 & $\mathrm{I}>\mathrm{II}$ \\
\hline & Arm Symptoms & $27.51 \pm 21.29$ & $20.33 \pm 19.84$ & $33.33 \pm 23.21$ & .026 & $\mathrm{III}>\mathrm{II}$ \\
\hline & Upset by Hair Loss & $30.77 \pm 36.42$ & $37.04 \pm 37.73$ & $51.85 \pm 39.97$ & .196 & NS \\
\hline
\end{tabular}

* Tukey HSD; NS: not significant; GHS/QOL= Global health status/ quality of life 